\title{
Salvage Technique for Complicated Hemodialysis Patients with Central Venous Occlusion
}

${ }^{1}$ Leszek Sulkowski, ${ }^{2}$ Maciej Matyja, ${ }^{3}$ Artur Pasternak

\section{ABSTRACT}

Background: Although safe, central venous catheters (CVCs) may cause several complications including central venous occlusions. The salvage access techniques are life-saving alternatives required for patients who have exhausted other access options.

Technique: We present a technique of placing a permanent catheter in the femoral vein facing the dilated collaterals. This is done in case of iliac vein and vena cava thrombosis following placement of multiple CVCs.

Conclusion: This technique might be an effective alternative to the translumbar approach when performed by an experienced operator in a well-equipped access center. It must not be attempted as a blind procedure.

Salvaged access can be considered when other access options have been exhausted and only translumbar or transhepatic inferior vena cava accesses are left.

Clinical significance: The CVCs remain the fastest, safe, and effective access for hemodialysis. As a last resort, lower extremity access may be considered. The presented salvage procedure is a modification of the routine CVC placement technique.

Keywords: Central venous catheter, Complications, Hemodialysis, Vascular access, Venography.

How to cite this article: Sulkowski L, Matyja M, Pasternak A. Salvage Technique for Complicated Hemodialysis Patients with Central Venous Occlusion. J Postgrad Med Edu Res 2018;52(3):152-154.

Source of support: Nil

Conflict of interest: None

\section{BACKGROUND}

Patients suffering from chronic renal failure require an adequate vascular access. The options are arteriovenous

\footnotetext{
${ }^{1}$ Consultant, ${ }^{2}$ Resident, ${ }^{3}$ Professor

${ }^{1}$ Department of General and Vascular Surgery, Regional Specialist Hospital, Czestochowa, Poland

${ }^{2}$ Department of General Surgery, Jagiellonian University Medical College, Kraków, Poland; Department of Endoscopic, Metabolic and Soft Tissue Tumors Surgery, Jagiellonian University Medical College, Kraków, Poland

${ }^{3}$ Department of Anatomy, Jagiellonian University Medical College, Kraków, Poland

Corresponding Author: Leszek Sulkowski, Consultant Department of General and Vascular Surgery, Regional Specialist Hospital, Czestochowa, Poland, e-mail: lecheque@wp.pl
}

fistula (AVF), graft, and CVC. ${ }^{1}$ For stable cases, AVF is the access of choice. ${ }^{1-3}$ Nevertheless, there is room for CVCs for unstable patients, cases of insufficient vessels for AVF creation, cases when AVF options are exhausted, ${ }^{4}$ and for dialysis while the created AVF has not developed yet. ${ }^{2}$

The salvage access techniques are life-saving alternatives required for patients whose other access options have been already exhausted and who developed stenoses or occlusions of central veins. ${ }^{5}$ The salvage procedures are needed infrequently, but they are more complex than routine accesses. ${ }^{5}$

The salvage access may be a translumbar or transhepatic inferior vena cava access, catheterization of small venous collaterals, and recanalization of occluded veins. ${ }^{5}$ The access teams responsible for AVF creation and CVC placement need to be familiar with salvage access techniques and aware of the complication rate.

\section{TECHNIQUE}

To present the technique and results, we introduce the case of a 59-year-old woman with a history of over 20 years of hemodialysis. During this period, she underwent AVFs on both wrists, forearms, and arms. Her history of multiple AVFs exhausted the possibility of AVF creation. Additionally, numerous catheters have been introduced into the internal jugular, subclavian, and iliac veins on both sides leading to occlusions of both internal jugular veins and the right subclavian vein. Attempted CVC placement into patent subclavian vein was followed by rupture of the superior vena cava above its severe stenosis and hemorrhage to the right pleural cavity. An immediate sternotomy was necessary to repair the rupture of stenosed superior vena cava. Finally, occlusion of superior vena cava and superior vena cava syndrome exhausted the jugular and subclavian CVC options. Following this, she underwent a series of femoral CVCs. The CVC placement to the left femoral vein led to a wide skin and subcutaneous tissue necrosis in the groin around the catheter. The profuse necrosis required a series of surgical excisions and needed to be treated for months. The peritoneal dialysis was abandoned because of past laparotomias.

Prior to the described procedure, vascular access just failed and our patient needed an immediate vascular access. The jugular and subclavian accesses had to be 


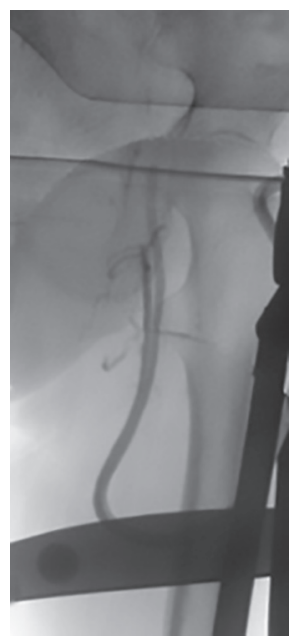

Fig. 1: Permanent catheter introduced to the left superficial femoral vein, distally from the total occlusion of the left iliac vein

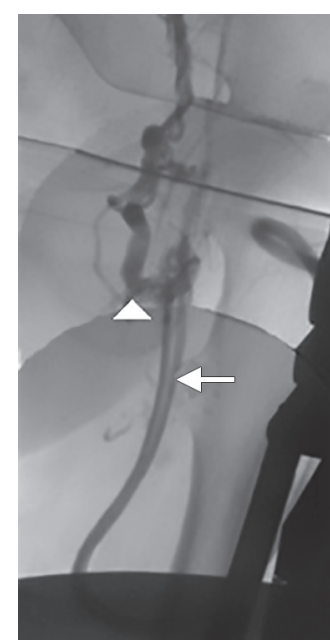

Fig. 2: Venogram showing collateral veins and total occlusion of the left iliac vein (arrow-tip of the catheter; arrowhead-dilated superficial epigastric vein)

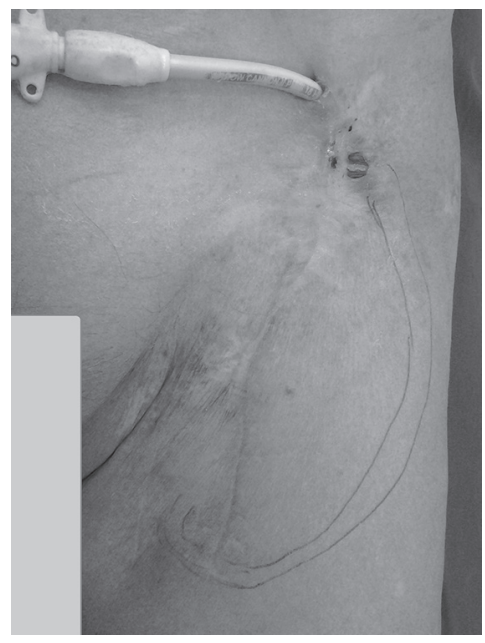

Fig. 3: The CVC tunneled toward the left hypogastrium allowing a comfortable access to the catheter lines. Scarred area in the left groin following necrosis

hemodialysis. ${ }^{6}$ Permanent hemodialysis CVCs placement ensures the hemodialysis in patients treated with chronic renal failure, in case of inability of AVF creation. ${ }^{7}$ The CVCs are a common vascular access in the final stage of kidney disease, with increased morbidity and mortality rate in comparison to AVFs and grafts. ${ }^{8}$ However, it may result in several early and late complications. ${ }^{6}$ The CVCs may cause venous injury, vein occlusion following stenosis and thrombosis, embolism, and catheter-related bloodstream infections. ${ }^{2-4,9-11}$ The risk of complications is enlarged by placing multiple catheters, longer duration of the CVCs, placement in subclavian vein instead of jugular vein, and location on the left side of the neck. ${ }^{2}$ In the presented case, the stenoses and occlusions of veins were demonstrated as well as superior vena cava rupture following an attempted catheter placement into left subclavian vein. The occlusion of superior vena cava shows signs of the superior vena cava syndrome ${ }^{12}$ and exhausts
The CVCs remain the fastest, safe, and effective ways to access the bloodflow in patients subjected to 
sites for vascular access on the upper extremity. ${ }^{11}$ This was also described in the presented case as a consequence of multiple CVC placements. Our patient developed several vein occlusions, including superior vena cava syndrome and asymptomatic iliac veins thrombosis. Fortunately, multiple superficial dilated collaterals were patent and visible in ultrasound examination and venogram (Fig. 2). Lacking both upper and lower extremities fistula options, the femoral catheter facing the dilated superficial epigastric vein was administered to achieve long-term vascular access and keep the translumbar approach as a last resort.

\section{CONCLUSION}

The technique that was used is a modification of a routine CVC technique and an extension of a routine catheter placement technique. It is an effective alternative for the translumbar approach, when performed by an experienced operator in a well-equipped access center. It must not be attempted as a blind procedure. It may ensure sufficient catheter flow. It can be considered as a salvage access when other access options have been exhausted and only translumbar or transhepatic inferior vena cava access is left.

\section{REFERENCES}

1. Torreggiani M, Scaramuzzi ML, Manini A, Castoldi F, Serpieri N, Maggi N, Sileno G, Migotto C, Esposito V, Montagna $F$, et al. Hemodialysis vascular access: everything you always wanted to know about it (but were afraid to ask). J Nephrol 2013 Sep;26(5):836-847.

2. Kotsikoris I, Zygomalas A, Papas T, Maras D, Pavlidis P, Andrikopoulou M, Tsanis A, Alivizatos V, Bessias N. Insertion of central venous catheters for hemodialysis using angiographic techniques in patients with previous multiple catheterizations. Eur J Radiol 2012 Sep;81(9):2270-2272.

3. Niyyar VD. Catheter dysfunction: the role of lock solutions. Semin Dial 2012 Nov-Dec;25(6):693-699.

4. Kumar NG, Dugan MM, Illig KA, Gillespie DL. Lower extremity arteriovenous fistula with central venous stenosis iliocaval stenting to treat venous outflow obstruction. J Vasc Surg 2011 Feb;53(2):487-488.

5. Denny DF Jr. Venous access salvage techniques. Tech Vasc Interv Radiol 2011 Dec;14(4):225-232.

6. Beigi AA, Kargari A, Ghaheri H, Davarpanahjazi AH. Comparison between two methods of central venous catheter placement in hemodialysis patients. J Isfahan Med School 2012 Jul;30(189):1-8.

7. Skandalos LK, Samaras AA, Karakatsanis AI, Ditsias TK, Filippidis AA, Mavromatidis KS, Koutsouflianiotis NK. Insertion of permanent hemodialysis catheters through the great saphenous vein. Int J Artif Organs 2012 Jul;35(7):520-524.

8. Haddad NJ, Van Cleef S, Agarwal AK. Central venous catheters in dialysis: the good, the bad and the ugly. Open Urol Nephrol J 2012 Jun;5(1):12-18.

9. Shingarev R, Allon M. Peripherally inserted central catheters and other intravascular devices: how safe are they for hemodialysis patients? Am J Kidney Dis 2012 Oct;60(4):510-513.

10. Napalkov P, Felici DM, Chu LK, Jacobs JR, Begelman SM. Incidence of catheter-related complications in patients with central venous or hemodialysis catheters: a health care claims database analysis. BMC Cardiovasc Disord 2013 Oct;13:86.

11. Bellows PH, Anaya-Ayala JE, Cheema ZF, Davies MG, Lumsden AB, Peden EK. Combined femoral vein transposition and iliac vein to suprarenal vena cava bypass as a last resort dialysis access. Ann Vasc Surg 2011 Feb;25(2):264.e5-264.e8.

12. Özbek IC, Sever K, Mansuroğlu D, Kaçar S Surgical treatment of catheter related superior vena cava syndrome without cardiopulmonary bypass in a patient with renal transplantation. Turk J Thorac Cardiovasc Surg 2013;21(1):187-190. 